\title{
AVALIAÇÃO DA ADERÊNCIA DE BIO-ÓLEO EM PAREDE DE TROCADOR DE CALOR DO TIPO CASCO E TUBO EM PLANTA DE PIRÓLISE DE BIOMASSA
}

\author{
L. G. G. PEREIRA ${ }^{1}$, F. S. J. LIMEIRA ${ }^{1}$ e C. A. M. PIRES ${ }^{1}$ \\ ${ }^{1}$ Universidade Federal da Bahia, Departamento de Engenharia Química \\ E-mail para contato: gabriel_murdoc@hotmail.com
}

\begin{abstract}
RESUMO - O volume de bio-óleo produzido em uma planta piloto de pirólise depende das variáveis operacionais tradicionais, assim como do escoamento do fluido no condensado. A aderência do bio-óleo nas paredes metálicas é um evento comum neste processo e provoca perdas consideráveis de produção. O objetivo do presente trabalho é avaliar a aderência do bio-óleo na parede dos condensadores da planta. Para isso, aspectos como a temperatura do bio-óleo, a temperatura da parede e a geometria do trocador de calor foram considerados como variáveis nessa análise. Os efeitos provocados sobre a massa retida de bio-óleo foram avaliados através dos ensaios realizados com base em planejamento de experimentos.
\end{abstract}

\section{INTRODUÇÃO}

As discussões a respeito dos problemas ambientais enfrentados pelo homem estão cada vez mais notórias atualmente. As mudanças climáticas estão em evidência nesse contexto, sendo causadas principalmente pela queima de combustíveis para a geração de energia. $\mathrm{O}$ aquecimento global é causado pelos gases de efeito estufa como, por exemplo, dióxido de carbono $\left(\mathrm{CO}_{2}\right)$, que é principalmente gerado pela utilização de combustíveis fósseis (CHOI et al., 2010). Diante da crescente preocupação com as questões ambientais e da redução das reservas de petróleo, a exploração de óleos vegetais para a produção de biocombustíveis surgiu como alternativa promissora ao uso dos combustíveis fósseis, além de promover a inclusão social e o desenvolvimento regional por meio do agronegócio (CORREIA, 2009).

Há várias tecnologias de conversão para produzir combustíveis líquidos, dentre elas, a pirólise rápida de biomassa tem experimentado um rápido desenvolvimento nos últimos anos, oferecendo um caminho alternativo para resolver problemas de escassez de combustível líquido. Uma vez que a biomassa é um recurso disponível em abundância na natureza, ela torna-se uma fonte energética bastante atrativa. Além disso, em contraste com outras fontes renováveis, a biomassa representa a única fonte de combustíveis líquidos, sólidos e gasosos (Bridgwater e Peacocke, 2000). 
Pirólise é a decomposição térmica que ocorre na ausência de oxigênio. No que diz respeito às condições operacionais utilizadas, ela pode ser definida como rápida ou lenta. As principais diferenças entre a pirólise lenta e rápida são as taxas de aquecimento e temperaturas máximas de reação. As taxas de aquecimento da pirólise lenta são tipicamente abaixo de 100 $\mathrm{K} / \mathrm{min}$ enquanto que a pirólise rápida pode alcançar taxas superiores a $1000 \mathrm{~K} / \mathrm{min}$. As temperaturas de reação são cerca de $300{ }^{\circ} \mathrm{C}$ e $500{ }^{\circ} \mathrm{C}$ para pirólise lenta e rápida respectivamente. Além disso, a pirólise lenta requer vários minutos ou mesmo horas, enquanto que a pirólise rápida é completa em menos de dois segundos (Bridgwater, 2011; Brown et al., 2010).

Não foram encontrados na literatura trabalhos sobre a aderência do bio-óleo nas paredes dos trocadores de calor numa planta de pirólise. Tendo em vista a importância da determinação da massa de bio-óleo produzida em uma planta piloto, e levando em consideração que a retenção de bio-óleo nos condensadores é comum, foi desenvolvida uma metodologia para avaliar esse evento em função de algumas variáveis do processo.

O presente trabalho foi feito para obter informações da aderência de bio-óleo nas paredes dos condensadores em função de parâmetros como a temperatura e geometria dos mesmos, a fim de auxiliar na quantificação de bio-óleo produzido em cada ciclo de produção. Foi determinada a massa de bio-óleo retida em tubos de aço inox nas condições definidas no planejamento de experimentos, e em seguida determinou-se a influência de algumas variáveis operacionais na massa retida de bio-óleo.

\section{MATERIAIS E MÉTODOS}

\subsection{Materiais empregados}

Com a finalidade de simular as condições de escoamento do bio-óleo nos condensadores, foram utilizados três tubos de aço inox, cujas características são mostradas na Tabela 1 a seguir:

Tabela 1 - Características físicas dos tubos de aço inox

\begin{tabular}{ccccc}
\hline Tubos & $\begin{array}{c}\text { Comprimento } \\
(\mathbf{m})\end{array}$ & $\begin{array}{c}\text { Diâmetro interno } \\
(\mathbf{m})\end{array}$ & $\begin{array}{c}\text { Diâmetro externo } \\
(\mathbf{m})\end{array}$ & $\begin{array}{c}\text { Área interna } \\
\left(\mathbf{m}^{2}\right)\end{array}$ \\
\hline 1 & $1,10 \mathrm{E}-01$ & $9,00 \mathrm{E}-03$ & $1,20 \mathrm{E}-02$ & $3,11 \mathrm{E}-03$ \\
2 & $1,30 \mathrm{E}-01$ & $9,00 \mathrm{E}-03$ & $1,20 \mathrm{E}-02$ & $3,68 \mathrm{E}-03$ \\
3 & $1,90 \mathrm{E}-01$ & $9,00 \mathrm{E}-03$ & $1,20 \mathrm{E}-02$ & $5,37 \mathrm{E}-03$ \\
\hline
\end{tabular}

Para o aquecimento dos tubos de aço inox, foi utilizada uma estufa Orion 515 da marca Fanem ${ }^{\circledR}$ modelo A-HT. O bio-óleo, por sua vez, foi aquecido num forno industrial da marca $\mathrm{Edg}^{\circledR}$ modelo 3000 3P-S. Para os procedimentos de pesagem, foi utilizada uma balança analítica de precisão da marca Shimadzu ${ }^{\circledR}$ modelo AW 220. Além disso, também foram utilizados béqueres, erlenmeyers, suporte, garras e luvas térmicas e de látex.

\subsection{Metodologia de trabalho}




\section{9 a 22 de outubro de 2014 \\ Florianópolis/SC}

A amostra de bio-óleo foi colocada em um erlenmeyer de $40 \mathrm{~mL}$, previamente aferido. Após a pesagem, o erlenmeyer foi levado para o forno industrial a fim de aquecer o bio-óleo na temperatura indicada pelo experimento. Do mesmo modo, o tubo de aço inox foi pesado na balança analítica e em seguida fixado no interior da estufa, na qual foram realizados os ensaios.

Com o conjunto aquecido, fechou-se uma das extremidades do tubo e verteu-se o bio-óleo no seu interior, a fim de impregnar por completo as paredes internas do tubo. Em seguida, a extremidade fechada do tubo foi aberta, possibilitando o escoamento do bio-óleo. Logo após o término do escoamento o tubo foi novamente pesado e deixado em repouso por um período de 24h, à temperatura ambiente, sendo novamente pesado. Uma vez registradas as massas do tubo, pôde-se determinar a quantidade de bio-óleo retida nas paredes internas.

\section{RESULTADOS E DISCUSSÃO}

A aderência do bio-óleo nas paredes dos trocadores de calor da planta piloto está relacionada ao processo de condensação e aglutinação das partículas contidas na névoa. $\mathrm{O}$ escoamento é influenciado pela sua viscosidade que, por sua vez, é influenciada pela temperatura. Sendo assim, de acordo com o procedimento experimental, foi avaliada a relação existente entre a massa retida e variáveis do processo, que são: temperatura do bio-óleo, temperatura dos tubos e comprimento dos tubos.

Segundo Montgomery et al. (2004), em experimentos onde se deseja estudar o efeito conjunto de vários fatores sobre uma resposta, frequentemente são utilizados os planejamentos fatoriais. $\mathrm{O}$ planejamento $2^{3}$ especificamente permite estimar os efeitos entre três fatores, sendo eles os principais (A, B e C), as interações de segunda ordem (AB, AC e BC) e de terceira ordem $(\mathrm{ABC})$. É importante salientar que ao utilizar planejamentos fatoriais com dois níveis, se supõe que os efeitos dos fatores são lineares. Apesar disso, mesmo considerando que a linearidade se mantenha apenas aproximadamente, o sistema $2^{\mathrm{k}}$ trabalhará adequadamente. Então, uma forma de preservar a linearidade dos efeitos provocados pelos fatores num experimento é a utilização de pontos centrais. Dessa forma, pode-se estimar também os erros experimentais sem influenciar nas estimativas usuais dos efeitos em um planejamento $2^{\mathrm{k}}$.

Os ensaios foram, portanto, conduzidos a partir do planejamento de experimentos $2^{3} \mathrm{com}$ adição de três pontos centrais. As faixas de trabalho das variáveis, mostradas na Tabela 2, foram identificadas da seguinte forma: (+) foi utilizado para o nível superior, (0) para o ponto central e (-) para o nível inferior.

Tabela 2 - Fatores e níveis utilizados no planejamento fatorial

\begin{tabular}{cccc}
\hline Fatores & $\begin{array}{c}\text { Nível Inferior } \\
(-)\end{array}$ & $\begin{array}{c}\text { Ponto Central } \\
0\end{array}$ & $\begin{array}{c}\text { Nível Superior } \\
(+)\end{array}$ \\
\hline A & $1,10 \mathrm{E}-01$ & $1,30 \mathrm{E}-01$ & $1,90 \mathrm{E}-01$ \\
B & 343,15 & 353,15 & 363,15 \\
C & 343,15 & 383,15 & 423,15 \\
\hline \multicolumn{4}{c}{ A $=$ Comprimento do Tubo (m), B = Temperatura do Tubo (K) e } \\
\multicolumn{3}{c}{ C $=$ Temperatura do Bio-óleo (K) }
\end{tabular}


A Tabela 3 mostra a matriz de planejamento de experimentos com os valores das respostas obtidos nos diferentes ensaios.

Tabela 3 - Matriz planejamento e valor das respostas para cada experimento realizado

\begin{tabular}{cccccc}
\hline Ensaios & A & B & C & Massa retida $(\mathbf{k g})$ & Massa retida 24h $(\mathbf{k g})$ \\
\hline 1 & - & - & - & $1,95 \mathrm{E}-04$ & $7,71 \mathrm{E}-05$ \\
2 & + & - & - & $7,10 \mathrm{E}-04$ & $7,03 \mathrm{E}-04$ \\
3 & - & + & - & $1,15 \mathrm{E}-04$ & $8,98 \mathrm{E}-05$ \\
4 & + & + & - & $2,71 \mathrm{E}-04$ & $1,71 \mathrm{E}-04$ \\
5 & - & - & + & $1,21 \mathrm{E}-04$ & $6,59 \mathrm{E}-05$ \\
6 & + & - & + & $2,20 \mathrm{E}-04$ & $1,24 \mathrm{E}-04$ \\
7 & - & + & + & $1,47 \mathrm{E}-05$ & $1,02 \mathrm{E}-05$ \\
8 & + & + & + & $2,19 \mathrm{E}-04$ & $1,58 \mathrm{E}-04$ \\
9 & 0 & 0 & 0 & $2,91 \mathrm{E}-04$ & $2,27 \mathrm{E}-04$ \\
10 & 0 & 0 & 0 & $2,98 \mathrm{E}-04$ & $2,46 \mathrm{E}-04$ \\
11 & 0 & 0 & 0 & $2,79 \mathrm{E}-04$ & $2,00 \mathrm{E}-04$ \\
\hline
\end{tabular}

Levando em consideração inicialmente os efeitos dos fatores na resposta, apresentados na Tabela 4, pode-se observar que apenas o efeito principal do fator A (Comprimento do tubo, m) é significativo ( $\mathrm{p}$-valor $\leq 0,05$ ). Os efeitos de interação entre dois ou mais fatores, por sua vez, são todos não significativos. Apesar disso, pode -se investigar as tendências dos outros efeitos na massa retida através de superfícies de resposta. Na Figura 1 é mostrada a superfície de resposta obtida para a massa retida em função dos fatores A e B. Pode-se observar que interação entre esses fatores contribui negativamente para os valores da resposta. A influência da temperatura na viscosidade do bio-óleo interfere no seu escoamento em superfícies.

Tabela 4 - Análise dos fatores A, B e C e seus efeitos na resposta Massa retida (g)

\begin{tabular}{ccccccc}
\hline Fator & Efeito & $\begin{array}{c}\text { Erro } \\
\text { padrão }\end{array}$ & $\mathbf{t}(\mathbf{3})$ & $\mathbf{p}$ & $\begin{array}{c}(-) \mathbf{9 5 , \%} \text { Cnf. } \\
\text { Limt }\end{array}$ & $\begin{array}{c}(+) \mathbf{9 5}, \% \text { Cnf. } \\
\text { Limt }\end{array}$ \\
\hline Mean/Interc. & 0,000263 & 0,000030 & 8,90346 & 0,002988 & 0,000169 & 0,000357 \\
A & 0,000214 & 0,000066 & 3,22672 & 0,048336 & 0,000003 & 0,000425 \\
B & $-0,000157$ & 0,000068 & $-2,28921$ & 0,106033 & $-0,000375$ & 0,000061 \\
C & $-0,000179$ & 0,000068 & $-2,61926$ & 0,079051 & $-0,000397$ & 0,000039 \\
A B & $-0,000063$ & 0,000068 & $-0,92518$ & 0,423112 & $-0,000281$ & 0,000155 \\
A C & $-0,000092$ & 0,000068 & $-1,34432$ & 0,271461 & $-0,000310$ & 0,000126 \\
B C & 0,000103 & 0,000068 & 1,50934 & 0,228353 & $-0,000115$ & 0,000321 \\
A B C & 0,000116 & 0,000068 & 1,69336 & 0,188962 & $-0,000102$ & 0,000334 \\
\hline
\end{tabular}

$\mathrm{A}=$ Comprimento do Tubo (m), B = Temperatura do Tubo (K) e $\mathrm{C}=$ Temperatura do Bio-óleo $(\mathrm{K})$

Sabe-se também que o aumento de viscosidade ocasionado pela diminuição da temperatura afeta a fluidez do bio-óleo, aumentando a sua resistência ao escoamento. Por outro lado, também é interessante salientar que a diminuição do comprimento ocasiona uma menor superfície de contato, diminuindo, portanto a aderência e consequentemente a resistência ao 


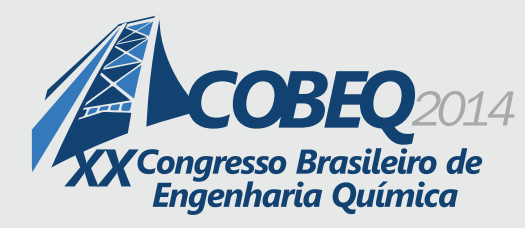

19 a 22 de outubro de 2014

Florianópolis/SC

escoamento. Por meio da superfície de resposta pode-se perceber que maiores valores de massa retida são obtidos para níveis inferiores do fator B e superiores do fator A. Porém, pode-se observar também que a variação no fator $\mathrm{C}$ não provoca uma mudança significativa na resposta, uma vez que este efeito não é significativo.

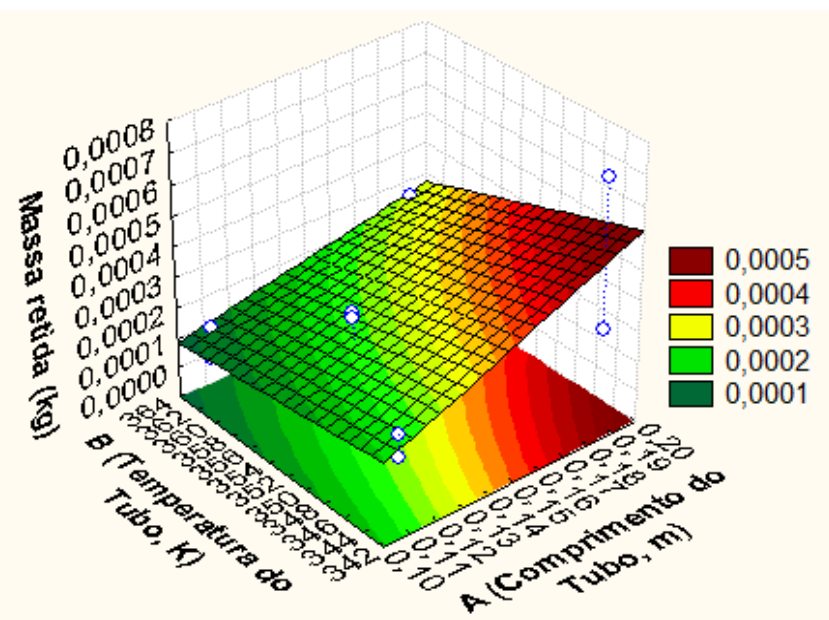

Figura 1 - Superfície de resposta obtida para massa retida $(\mathrm{kg})$ em função dos fatores A e B.

Do mesmo modo que os fatores $\mathrm{A}$ e $\mathrm{B}$, os fatores $\mathrm{A}$ e $\mathrm{C}$ contribuem negativamente para a resposta massa retida (g). Maiores valores de massa retida são obtidos para maiores valores de do fator A e menores valores do fator C. Considerando a interação entre eles, uma mudança no fator B não proporciona mudança significativa nos valores da massa retida, analogamente ao que foi observado no caso anterior. Este efeito pode ser visualizado por meio da superfície de resposta apresentada na Figura 2.

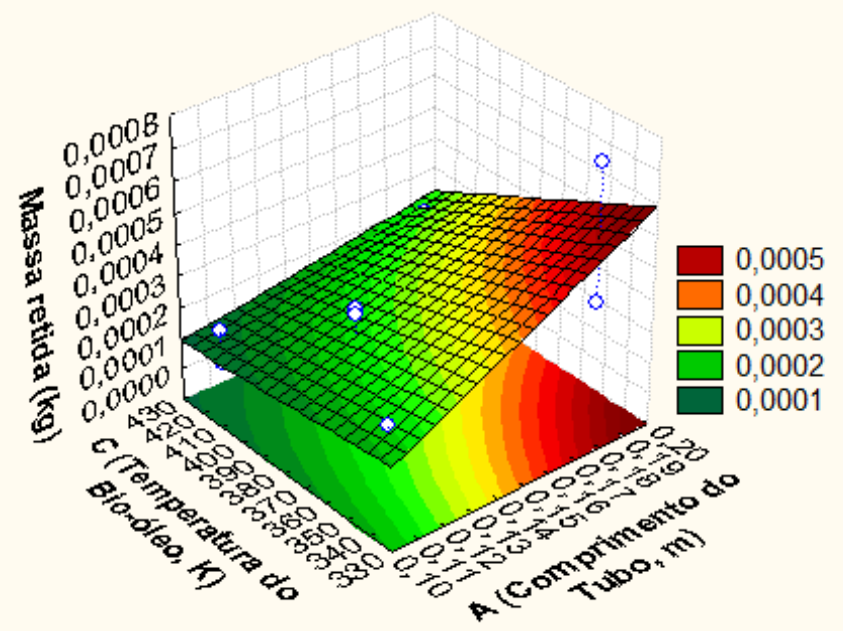

Figura 2 - Superfície de resposta obtida para massa retida $(\mathrm{kg})$ em função dos fatores A e C. 
Quando é feita a análise da interação entre os fatores B e C, porém, observa-se uma maior variação da massa retida com o fator A. Isso comprova a maior significância do efeito principal do fator A apresentado pela Tabela 4. Além disso, o efeito de interação entre fatores B e C é negativo, isto é, aumentando-se simultaneamente os seus níveis haverá uma redução na massa retida. A Figura 3 mostra a superfície de resposta correspondente a este efeito.

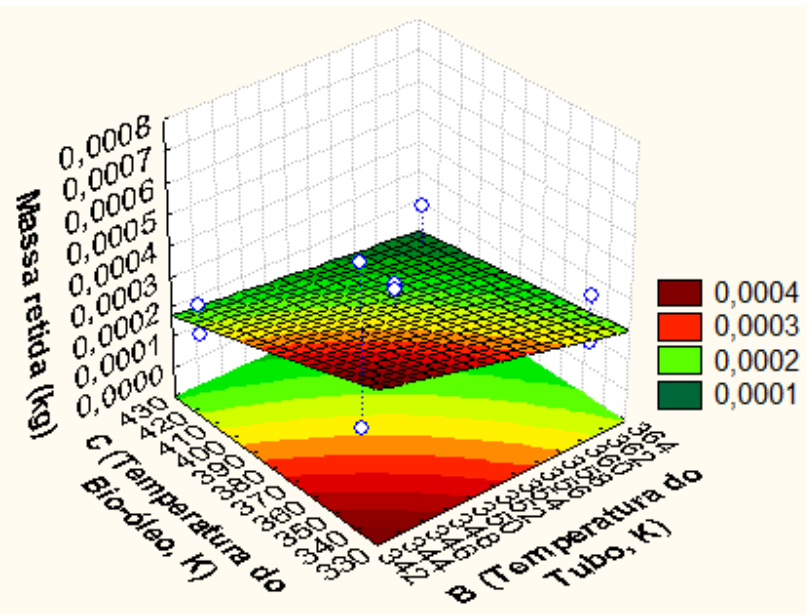

Figura 3 - Superfície de resposta obtida para massa retida $(\mathrm{kg})$ em função dos fatores B e C.

Adicionalmente, analisou-se a diferença obtida entre a massa retida antes e após o período de 24 horas em cada ensaio. Os dados apresentados na Tabela 3 permitem concluir que a massa retida média e a massa retida média após 24 horas são, respectivamente, 2,48E-04 kg e 1,88E-04 $\mathrm{kg}$. Dessa forma 24,2\% do bio-óleo foi volatilizado em 24 horas. Dividindo-se as massas retidas pelas áreas de contato em cada tubo, apresentadas na Tabela 1, pode-se obter também a massa retida média por unidade de área de cada ensaio. Os valores são apresentados na Tabela 5.

Tabela 5 - Massa de bio-óleo retida por unidade de área

\begin{tabular}{cccc}
\hline Ensaios & $\begin{array}{c}\text { Massa retida } \\
(\mathbf{k g})\end{array}$ & $\begin{array}{c}\text { Massa retida por área } \\
\left(\mathbf{k g} / \mathbf{m}^{2}\right)\end{array}$ & $\begin{array}{c}\text { Desvio em relação } \\
\text { à média }\end{array}$ \\
\hline 1 & $1,95 \mathrm{E}-04$ & $6,28 \mathrm{E}-02$ & 0,00 \\
2 & $7,10 \mathrm{E}-04$ & $1,32 \mathrm{E}-01$ & 0,07 \\
3 & $1,15 \mathrm{E}-04$ & $3,68 \mathrm{E}-02$ & $-0,02$ \\
4 & $2,71 \mathrm{E}-04$ & $5,04 \mathrm{E}-02$ & $-0,01$ \\
5 & $1,21 \mathrm{E}-04$ & $3,88 \mathrm{E}-02$ & $-0,02$ \\
6 & $2,20 \mathrm{E}-04$ & $4,09 \mathrm{E}-02$ & $-0,02$ \\
7 & $1,47 \mathrm{E}-05$ & $4,73 \mathrm{E}-03$ & $-0,05$ \\
8 & $2,19 \mathrm{E}-04$ & $4,07 \mathrm{E}-02$ & $-0,02$ \\
9 & $2,91 \mathrm{E}-04$ & $7,91 \mathrm{E}-02$ & 0,02 \\
10 & $2,98 \mathrm{E}-04$ & $8,10 \mathrm{E}-02$ & 0,02 \\
11 & $2,79 \mathrm{E}-04$ & $7,60 \mathrm{E}-02$ & 0,02 \\
\hline Média & $2,48 \mathrm{E}-04$ & $5,85 \mathrm{E}-02$ & \\
\hline
\end{tabular}


A massa retida média por unidade de área, nesse caso $5,85 \mathrm{E}-02 \mathrm{~kg} / \mathrm{m}^{2}$, representa a quantidade máxima de bio-óleo retida em um trocador de calor por unidade de área. $\mathrm{O}$ uso deste valor para estimar a quantidade máxima de bio-óleo retida mostra-se adequado, já que os desvios encontrados para cada ensaio são próximos de zero.

\section{CONCLUSÃO}

O estudo proposto identificou a importância do comprimento do trocador de calor na coleta do bio-óleo produzido. Uma vez que o comprimento dos condensadores interfere significativamente na aderência do fluido nas suas paredes internas, a sua especificação se torna um fator de extrema importância no dimensionamento global da planta. $\mathrm{O}$ valor médio da massa de bio-óleo retida nas paredes do condensador pode ser utilizado para identificar, por exemplo, a quantidade mínima de biomassa processada no reator a partir da qual o bio-óleo será coletado. Este trabalho alcançou o objetivo proposto, porém, outras variáveis deverão ser avaliadas de maneira correlacionar a retenção de bio-óleo à viscosidade do fluido.

\section{REFERÊNCIAS}

BRIDGWATER, A. Review of fast pyrolysis of biomass and product upgrading. Biomass and bioenergy xxx, p. 1-27, 2011.

BRIDGWATER, A.; PEACOCKE, G. Fast pyrolysis processes for biomass. Renewable and Sustainable Energy Reviews 4, p.1-73, 2000.

BROWN, T; WRIGHT, M; BROWN, R. Estimating profitability of two biochar production scenarios: slow pyrolysis $v s$ fast pyrolysis. Modeling and Analysis, p. 1-15, 2010.

CHOI, H. S.; CHOI, Y. S.; PARK, H. C. The influence of fast pyrolysis condition on biocrudeoil yield and homogeneity. Korean J. Chem. Eng., p. 1-6, 2010.

CORREIA, I. Extração e pirólise do óleo de girassol (Helianthus annus L.) visando a produção de biocombustíveis. Dissertação (Mestrado)-Universidade Federal do Rio Grande do Norte, Natal, p. 1-94, 2009.

MONTGOMERY, D.C.; RUNGER, G.C.; HUBELE, N.F. Estatítica Aplicada à Engenharia. Rio de Janeiro: LTC, 2004. 